\title{
The early solvay councils and the advent of the quantum Era
}

\author{
Franklin Lambert ${ }^{1, a}$, Frits Berends ${ }^{2, b}$, and Michael Eckert ${ }^{3, c}$ \\ ${ }^{1}$ Physics Department, Vrije Universiteit Brussel, 2 Pleinlaan, 1050 Brussels, Belgium \\ ${ }^{2}$ Institute Lorentz for theoretical physics, Leiden University, The Netherlands \\ ${ }^{3}$ Forschungsinstitut, Deutsches Museum, Museumsinsel 1, 80538 München, Germany
}

\section{Introduction}

In 2011, an international workshop "The Early Solvay Councils and the Advent of the Quantum Era" took place in Brussels at the Royal Belgian Academy. Its main purpose was to discuss and to publicize the impact of the early Solvay Councils on the birth of quantum theory and on the development of modern physics. It also aimed at making the broader public aware of the role played in these processes by Solvay's Institute of Physics, a world première in physics and one of the earliest international foundations in science.

The workshop was an occasion to revisit the circumstances which prompted Ernest Solvay to convene the 1911 Council - at Walther Nernst's request - and to perpetuate the initiative up to the present day, by the creation of the International Institute of Physics.

Special attention was paid to Solvay's close relationship with Hendrik A. Lorentz, the famous Dutch theoretician whose brilliant chairmanship of the Council was admired by all participants. The deep spirit of mutual understanding between Lorentz and Solvay matched with their common desire to encourage exploratory research in the fundamentals of physics. These two factors proved decisive: they enabled Solvay to found his International Institute of Physics (ISIP) within a period of six months.

The workshop focused on the first two Solvay Councils - Solvay I and Solvay II - which to a certain degree encapsulated the short-lived promise of a harmonious world based on the constant progress of science, sustained by the regular exchange of results and ideas in a spirit of "olympic internationalism". A dream which, as we know, collapsed with the outbreak of the first World War.

This focus provided an opportunity to report on ISIP's main activity during its first years of existence: the concrete support of fundamental research by means of subsidies, granted by an independent Scientific Committee to applicants of all nationalities, without regard to their notoriety.

The fact that distinguished members of this international Committee - among them Marie Curie, Hendrik Lorentz, Walther Nernst and Ernest Rutherford - took

\footnotetext{
a e-mail: flambert@vub.ac.be

b e-mail: berends@lorentz.leidenuniv.nl

c e-mail: m.eckert@deutsches-museum.de
} 
the trouble to spend part of their precious time in selecting the beneficiaries of Solvay grants, stands as a moving testimony of pre-war faith in internationalism as a means of achieving peaceful progress in science. More than 40 research projects, originating from various European countries, Russia and America, benefited from Solvay grants between 1912 and 1914. Six of them contributed to experimental research that would be crowned by a Nobel Prize.

A further point of interest was ISIP's fate during WWI, when international scientific relations were brutally interrupted and a long period of mistrust persisted between nationals from the two sides. Lorentz's remarkable role in this context, his long-standing efforts to re-establish scientific contacts among all parties, in agreement with Solvay's personal views on the matter, are elements which, against all odds, enabled the Physics Institute to survive the crisis.

The workshop also addressed the social and scientific environment of the Institute's founder, the rapidly evolving aspects of physical research during the first decades of the twentieth century, the role of the "Solvay model" and its impact on the emergence of international networks.

As to the program of the meeting, it comprised seven lectures, followed by a general round table discussion. One of the invited speakers, Dieter Hoffmann, was unable to participate and to contribute. The original program can be found at $U R L$. No proceedings of that workshop were published at the time, but it was agreed to consider the publication of a special issue as follow-up project over the following years. Eventually, six contributions, described in the following section, have been collected in the present volume.

\section{Organization of the volume}

A first paper, by Franklin Lambert, is devoted to the origin, the agenda and the main results of Solvay I. Its purpose is to revisit the "legend" which surrounds this historical meeting, and to confront it with the facts. The paper also aims at re-establishing the truth about the actual proceedings of the Council, by disclosing some remarkable discrepancies between the official report, published by Gauthier-Villars in 1912, and the notes taken during the conference by Maurice de Broglie, one of the scientific secretaries.

Some puzzling elements related to the origin of Solvay I and to Solvay's position with regard to his international foundation for physics, are discussed in the light of the Scientific Notes, written by Solvay during the years 1910-1914.

In a following paper, John Heilbron reports on a number of peculiar elements in the organization of Solvay I and Solvay II, with an emphasis on the intriguing aspects of the British participation to these first two Solvay Councils. The analysis throws new light on a variety of open quenstions, such as the reason for the notable difference in the reaction of the British invitees in 1911 and 1913, and the extent to which these Councils affected the evolution of physical research in England. It also clarifies the way in which Bohr was influenced in his work by the early Solvay discussions.

Heilbron completes his paper with a thorough review of two reports - Jeans' report at Solvay I and Thomson's report at Solvay II - which, in retrospect, reveal something of the "enduring weakness of the old Cambridge school of physical mathematics".

Michael Eckert's paper deals with a theoretical novelty presented at Solvay I: Sommerfeld's ill-fated attempt to produce a quantum theory based on a new hypothesis (the $h$-hypothesis) that would make it applicable to non-periodic processes, such as radioactive phenomena and the photoelectric effect.

After reporting extensively on the source of the $h$-hypothesis - Sommerfeld's longstanding quest of the nature of X-rays - Eckert reviews his search for experimental 
evidence in support of the new theory, and discusses its reception at Solvay I. He also describes the subsequent decline of the $h$-hypothesis, compensated by the spectacular rise of X-ray spectroscopy and crystallography, which also originated in Sommerfeld's Munich laboratory, with the discovery of Laue, Friedrich and Knipping. These remarkable developments would become central issues at Solvay II.

Two of the following papers are devoted, respectively to Ernest Solvay - the man who made the first "Quantenkongress" and the International Institute for Physics possible - and to Hendrik A. Lorentz - the man who made them sucessful (a statement borrowed from John Heilbron).

Nicolas Coupain's paper is a well-documented report on the various aspects of the life and works of Ernest Solvay. Based on recent investigations in Solvay's private archives, it produces a more faithful portrait of the Institute's founder than that of a successful industrialist eager to be remembered as a magnanimous patron of science. Thanks to a careful study of Solvay's social and scientific programs, his surroundings, his working methods and international networks, Coupain succeeds in giving new insight into the complex nature of an exceptional organizer, whose actions and attitudes are still far from being fully understood.

Frits Berends' paper is a comprehensive account of the history, the personality and the multiple talents of Hendrik A. Lorentz, who played a pivotal role in shaping and perpetuating the Solvay Institute of Phyiscs. The paper's first focus is on the Dutchman's outstanding leadership as chairman of the Institute's Scientific Committee, and on the way in which this involvement added to his influence on the international sphere. Another important part of the paper is devoted to Lorentz's constructive attitude during and after WWI - his strong wish to remain objective and helpful during the bitter conflict, and his post-war faith in the need to restore international scientific relations after a period of time, a feeling shared by Solvay in spite of Belgium's tragic fate.

The last paper is a report by Arne Schirrmacher on the role played by Solvay I in the creation of the Göttingen Institute of Theoretical Physics, where, thanks to the efforts of Hilbert and the pioneering works of Born and Debye, quantum mechanics was formulated for the first time. It provides a welcome complement to Eckert's paper, where Munich is singled out as one of the leading German centers for research on quanta.

Schirrmacher's main point is the fact that Solvay I inaugurated a new model: that of a privately funded high profile "agenda setting" meeting, at which a specific issue is discussed by a limited number of participants on the basis of pre-circulated papers, with the understanding that papers and discussions will be published after the meeting. According to this view, the principal merit of the first Solvay council was the introduction of a model that would succeed in making the early quantum theory popular with scientists and with the broader public.

\title{
Titles of the papers, authors and abstracts
}

\author{
"Einstein's Witches' Sabbath in Brussels: The Legend and the Facts" \\ by Franklin J. Lambert
}

\section{Abstract}

This paper is about the first Solvay Council on Physics, its surprising origin and its far reaching consequences. In spite of the various accounts that have been given by several authors - they include historians of science, but also outstanding scientists, such as Leon Rosenfeld, Niels Bohr and Eduardo Amaldi - it appears that only 
limited attention was paid so far to the more singular aspects of this legendary meeting, and to the peculiar circumstances which led to its convening. This fact may be due to the restricted availability of relevant documents, many of which are located in different archives. It also reflects the rather abstract character of Ernest Solvay's Institute of Physics - an Institute without a permanent staff, governed by geographically separated bodies: a scientific committee with a chairman in Haarlem, a secretary in Copenhagen and an administrative committee in Brussels.

One of the purposes of the paper is to fill this gap by revisiting the course of events which led to Solvay's invitation of June 1911. Another aim is to present a brief, yet balanced, account of the deliberations which took place in October-November 1911, by pointing at some elements that may be regarded as highlights of the Council, and by focusing on the contrasting aspects of its main results: the contrast between the Council's disappointing conclusions on the one hand, and its positive consequences on the other hand. Special attention in this context is given to the unexpected concern about the validity of Planck's law, expressed by Emil Warburg, and to the apparent contradictions in Einstein's private reactions to the outcome of the Brussels meeting.

The paper also aims at restoring the truth about some facts regarding the Solvay reports and their discussion, by revealing the discrepancies between the official account - the Gauthier-Villars volume "La théorie du rayonnement et les quanta", published in 1912, and the actual proceedings of the conference, based on notes taken during the meeting by Maurice de Broglie. A significant point is the removal from the official volume of an important remark made by Planck about the status of the "heat theorem" during the discussion of Nernst's report.

A last section of the paper is devoted to one of the durable consequences of the Council: Solvay's decision to create the International Institutes of Physics. This section serves as an introduction to Frits Berends' paper: "Lorentz, the Solvay Councils and the Physics Institute".

"British Participation in the First Solvay Councils on Physics"

by John L. Heilbron

\section{Abstract}

Analysis of the makeup and contributions of the British contingents to the first two Solvay Councils can elucidate the character of British mathematical physics and its internal dynamics at a critical time in its development.

The paper provides this analysis, outlines the process of selection of the participants, parses the meaning of "international" in the Solvay context, and offers an explanation of the differential attendance of the British at the two Councils. Most of those invited to the first refused whereas all but one of those invited to the second accepted. The unusual social and scientific views of Ernest Solvay help to explain this divergence.

"From X-Rays to the $h$-Hypothesis: Sommerfeld and the Early Quantum Theory 1909-1913"

by Michael Eckert

\section{Abstract}

Sommerfeld was deeply interested in the nature of X-rays. In 1900 he concluded from diffraction experiments on slits that, if X-rays are electromagnetic radiation, their "impulse width" should be of the order of magnitude of the size of molecules. In 1905 Sommerfeld regarded it "a shame that after ten years after Röntgen's discovery one still does not know what is going on with X-rays".

When he became Röntgen's colleague a year later, he perceived this shame even more as a challenge. By that time it was discovered that X-rays come in 
two varieties. One sort of X-rays was independent of the anti-cathode material and could be explained by Sommerfeld in 1909 as "Bremsstrahlung", i.e. as an electromagnetic radiation caused by the deceleration of electrons at their impact in the anti-cathode. The other part had the character of a fluorescent radiation. The "Bremsstrahlung" was polarized and displayed an angular distribution of intensity with a characteristic shape dependent on the energy of the electrons at the impact in the anti-cathode; the other part was unpolarized and characteristic for the material of the anti-cathode.

Sommerfeld's "Bremsstrahlen"-theory could not be elaborated without further assumptions about the impact of electrons in the anti-cathode. Sommerfeld closed his theory by a quantum hypothesis: He linked the time required to stop an electron, $t$, and the energy released in this process, $E$, to Planck's quantum of action, $h$, via $t E=h$. This so-called $h$-hypothesis became the subject of Sommerfeld's presentation at the first Solvay Conference. Although met with criticism, the quantum effort at Munich raised curiosity.

Sommerfeld attempted to verify this hypothesis theoretically and experimentally in his institute with Walther Friedrich, his experimental assistant. Friedrich, a doctoral student from Röntgen's institute, was persuaded however by Max Laue, then Sommerfeld's Privatdozent, to perform another experiment which led to the discovery of X-ray diffraction in crystals. Their sensational result, obtained in spring 1912, was among the subjects for the second Solvay Conference in 1913. Sommerfeld regarded this experiment the most important achievement of his institute - and silently buried the $h$-hypothesis which turned out to be one of the dead-ends of the early quantum theory.

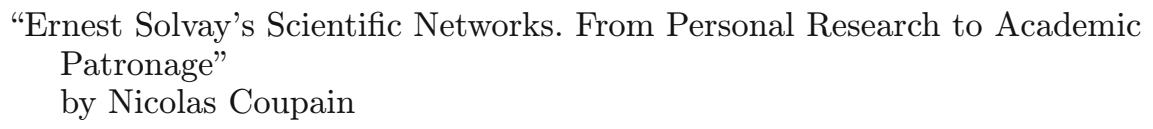

\section{Abstract}

Ernest Solvay was a multifaceted man. A successful captain of industry, he got known in the second part of his life as a magnanimous sponsor of academic science. His most notable achievements in this field are the creation of a series of university institutes in Brussels as well as the co-organization of the conferences of physics and chemistry that bear his name and are still held today.

A famous picture of 1911 depicts this man deprived of any university degree, surrounded by the brightest scientists of the time. The often conveyed image of a selfmade man leads to an underestimation of his networking and delegation capabilities. Recent investigations in his private archives as well as in "his" company archives shed new light on his organizational skills in the scientific arena.

This paper focuses especially on this facet, and intends to analyze how Solvay behaved as an organizer of science. Three partially overlapping levels are discussed in sequence: the Solvay Company level, his personal level, and the academic level. The paper identifies the key actors in these areas, and evaluates the intensity of control and delegation exerted by Ernest Solvay in each of these spheres.

"Lorentz, the Solvay Councils and the Physics Institute"

by Frits A. Berends

\section{Abstract}

This paper describes the crucial role which Lorentz played in shaping and continuing the Solvay Councils and the Physics Institute. At the same time it will become clear that Lorentz' intensive involvement in these activities added significantly to his influence on, and recognition in, the international physics community. 
The first Solvay Council in 1911 was an initiative of the German physical chemist Walther Nernst. It was generously supported by the wealthy industrialist and philantropist Ernest Solvay. About five months before the Council's start Nernst invited Lorentz to chair the meeting. That was no simple task in view of the fundamental problem of the quanta and the practical problem of communication in different languages. Lorentz's way of presiding the conference impressed all participants.

When, after the meeting, Solvay was willing to support research in the field, it was only natural to ask Lorentz for a plan. Within two months Lorentz provided Solvay with a draft which would serve as an outline for the statutes of an institute. The international Solvay Institute of Physics was founded on 1 May 1912. It would support research proposals in a specified field and would regularly organize Councils. An international scientific committee would decide on grants which could be requested from everywhere. Between the Institute's beginnings and the outbreak of WWI, 97 requests were considered and 40 proposals - originating from 7 countries - were accepted.

A second Council took place in 1913. Lorentz was given the possibility to spend considerable time on chairing the scientific committee when in 1912 his full time professorship in Leiden was changed into a part-time one.

During WWI Lorentz maintained contacts with Solvay and with several of his foreign colleagues in the countries at war. He tried to remain objective, impartial and helpful, and did not lose hope that pre-war international scientific relations would eventually be re-established. After the war he had to accept the Allied exclusion of the scientists of the Central Powers, but considered this a temporary necessity which should be lifted as soon as possible. He therefore advocated the continuation of the Solvay Physics Institute. At the time, this idea was far from obvious, but it was endorsed by Solvay.

After two Councils without participants from the Central Powers the administrative committee decided in 1926 to lift this exclusion for the fifth Council, and to accept the idea of inviting Einstein to become a member of the scientific committee. This happened after a visit of Lorentz to King Albert in order to explain the intentions of the committee. Thus, the way was paved for a truly international Council in 1927.

"Who Made Quantum Theory Popular with Physicists and Beyond?"

by Arne Schirrmacher

\section{Abstract}

My paper considers the impact of the early Solvay meetings from a perspective of popularization, i.e. looking at audiences besides science. In asking "Who made quantum theory popular?" I investigate whether this unusual congress introduced a kind of mechanism - institutional, disciplinary, popularizing or other - that had been recognized and applied also elsewhere.

My interpretation of the early Solvay conferences, on the one hand, dispenses with linear stories often found with older accounts, e.g. that the Solvay meetings Nos. 1, 2 and 5 supposedly laid the foundations of quantum theory altogether. On the other hand, I attempt at dispelling the "three miracles" Peter Galison (2007) has found in the history of the first Solvay meeting. He was right to stress that the meetings were not so much spectacular turning points in the history of physics but rather "served as sites for powerful reviews of the field" and were "catalysts for intellectual and social networks". However, neither the "precise balance between two philantropic forces" in Ernest Solvay's motivation, nor Lorentz's brilliant guidance of the discourse, nor the "presence and prior contributions" of Einstein, I would like to be willing to qualify in any way as miracles. There were good reasons, I argue, to give Lorentz the role he 
filled, and to invite Einstein; also Nernst may have made it clear enough to Solvay, what role would give him the most appreciation.

My thesis is that the success of the first Solvay meeting did not much rely on miracles, but was a successful unfolding of a meticulously devised model - call it the Solvay model, or probably more accurately, the Nernst model. This model can be characterized as an externally-funded, agenda-setting, high-profile and international meeting of scientists concerned with one novel scientific problem or field, where select pre-circulated papers of some participants were discussed with more invited discussants, and later its papers and discussions were published for reaching a broader scientific audience as well as informing a more general audience, and all this with the aim to have follow-up meetings as well as a grant giving institution promoting research in the chosen field.

For such a model, it obviously needed a Nernst, a Solvay and an interested scientific community, or to put it more generally, an organizer driven by a scientific problem he had encountered and which he wanted to dominate, a Philantropy that can offer funds and institutional resources, and also some disciplinary space, within which a new scientific subfield can be established. I test this model with two cases, which may be called Solvay 1.5 and Solvay 16.5, relating to high-profile meetings at Göttingen in 1913 and San Francisco in 1977.

\section{About the authors}

Frits Berends is Professor Emeritus of Theoretical Physics at the Lorentz Institute of the University of Leiden. He is an expert of H.A. Lorentz's activities in the public sphere, more particularly as chairman of the Scientific Committee of the International Solvay Institute of Physics (ISIP) from 1912 till 1928. Dr. Berends has done substantial research on ISIP, in Haarlem (Noord-Hollands Archief), Brussels (Archives de l'Université Libre de Bruxelles) and Paris (Archives de l'Ecole supérieure de physique et de chimie industrielles de la Ville de Paris, ESPCI). He is the author of "Hendrik Antoon Lorentz: His Role in Physics and Society" (J. Phys. Condens. Matter, 21, 2009) and co-author with Franklin Lambert of "Einstein's Witches' Sabbath: the First Solvay Council on Physics" (Europhysics News 42/5, 15, 2011). He wrote a booklet "Verhalen rond een foto", published in 2014 by the Royal Holland Society of Sciences and Humanities in Haarlem. It describes the exceptional national and international tribute paid to Lorentz on the occasion of the golden jubilee of his doctorate in 1925 .

Nicolas Coupain holds a M. A. in History from the Université Libre de Bruxelles. A specialist in business history, he has published books on the history of the retailing business in Belgium (La distribution en Belgique. Trente ans de mutation, Racine, 2005; also available in Dutch) and the Belgian automobile family firm D'Ieteren (Histoire financière du Groupe D'Ieteren, 1805-2005, Bruxelles, D'Ieteren, 2005). He is currently advisor of the Solvay Group as Heritage Manager and, together with Kenneth Bertrams and Ernst Homburg, has published a book on the history of the Solvay Company: "Solvay, History of a Multinational Family Firm", New York, Cambridge University Press, 2013, as well as a filmed documentary

Michael Eckert is an expert of the work of Arnold Sommerfeld, one of the founding fathers of the "old quantum theory" and an important member of the first Solvay Council. Dr. Eckert holds a PhD in theoretical physics. He spent most of his career as a historian of physics at the Forschungsinstitut of the Deutsches Museum in Munich, to which he is affiliated after his retirement in 2014 as an Honorary Member. He has published a book on Sommerfeld's School (1993), a two-volume edition of Sommerfeld's scientific correspondence (2000 and 2004), a history of fluid dynamics 
(2006), biographies of Heinrich Hertz (2010) and Sommerfeld (2013), and a review of Sommerfeld's work in fluid dynamics published in the Annual Review of Fluid Mechanics (2015).

John L. Heilbron is Professor of History and Vice-Chancellor Emeritus at the University of California, Berkeley; also Senior research Fellow at Worcester College, Oxford. He is an expert of the history of physics and astronomy, who directed, together with Thomas Kuhn, the Joint Project "Sources for History of Quantum Physics" of the American Physical Society and the American Philosophical Society (19611964). Dr. Heilbron is a member of the Royal Sweedish Academy of Science, and the author of many books, including "The Dilemmas of an Upright Man: Max Planck and the Fortunes of German Science" (Harvard University Press, 2000), and "Ernest Rutherford and the Explosion of Atoms" (Oxford University Press, 2003). He obtained in 1993 the George Sarton Medal of the History of Science Society, and in 2006 the Abraham Pais Prize for History of Physics. In 2013 he was invited to present a report at the $25^{\text {th }}$ Solvay Conference on Physics, entitled: "The First Solvay Council, a Sort of Private Conference".

Franklin Lambert is Professor Emeritus of Mathematical Physics at the Vrije Universiteit Brussel, where he also lectured on the history of modern physics. He has been involved in the activities of the International Solvay Institutes of Physics and Chemistry since 1995, as a member of the administrative board and as a deputy director between 2003 an 2009. He recently engaged in archival research which aims at providing a comprehensive account of the Solvay Councils on Physics during the period 1911-1939. He contributed to the book "La fabrique internationale de la science", published in 2010 by la Revue Internationale Germanique, CNRS Editions. Together with F. Berends, he published "Einstein's Witches' Sabbath: the First Solvay Council on Physics" (Europhysics News, 42/5, 15, 2011) and two booklets edited by the Service des Archives et Bibliothèques de l'Université Libre de Bruxelles: "Le Conseil Solvay 1911, une première mondiale en physique" (2011), and "Fondation de l'Institut international de chimie Solvay, couronnement d'un jubilé industriel" (2013).

Arne Schirrmacher has worked as a historian of science at the Deutsches Museum in Munich for roughly a decade, and has collaborated with the Berlin Max Planck Institute for the History of Science both in a project on the history of physics and on $20^{\text {th }}$ century science communication. Since 2010 he is based as a senior researcher at the history department of the Humboldt Universität zu Berlin. His educational background lies in physics, biology and philosophy, which he studied at Hamburg, Oxford and also Munich, where he received a $\mathrm{PhD}$ in mathematical physics before turning fully to the history of modern mathematical sciences. He has been Visiting Scholar at UC Berkeley's Office for the History of Science and Technology in 2011, Guest Professor at the Berlin Hermann von Helmholtz Center for Cultural Techniques and Erasmus Exchange Lecturer in Barcelona in 2013. His latest publication is "Establishing the Quantum in Göttingen": David Hilbert, Peter Debye and Max Born in Context (1900-1926), in "Quantum Networks" edited by Jürgen Renn, Edition Open access, Berlin 2015, pp. 247-380.

\section{Background information on the first two Solvay Councils (1911 and 1913)}

Solvay I: "La théorie du rayonnement et les quanta".

List of participants (as mentioned in the Council's Proceedings, edited by P. Langevin and M. de Broglie, Paris, Gauthier-Villars, 1912).

Chair: H.A. Lorentz (Leiden). 
Members

For Germany: W. Nernst (Berlin), M. Planck (Berlin), H. Rubens (Berlin), A. Sommerfeld (Munich), W. Wien (Wurzburg), E. Warburg (Charlottenburg). For England: J.H. Jeans (Cambridge), E. Rutherford (Manchester).

For France: M. Brillouin, Mme Curie, P. Langevin, J. Perrin and H. Poincaré (Paris). For Austria: A. Einstein (Prague), F. Hasenöhrl (Vienna).

For Holland: H. Kamerlingh Onnes.

For Denmark: M. Knudsen.

Members who could not be present in Brussels: Lord Rayleigh (London), J.D. van der Waals (Amsterdam).

Secretaries: R.B. Goldschmidt (Brussels), M. de Broglie (Paris) and F.A. Lindemann (Berlin).

Collaborators of Ernest Solvay: E. Herzen and G. Hostelet (Brussels).

Solvay reports:

"Sur l'application au rayonnement du théorème de l'équipartition de l'énergie" par H.A. Lorentz.

"The kinetic theory of specific heats, according to Clausius, Maxwell and Boltzmann" by J.H. Jeans.

"Experimentele Prüfung der Planck'schen Formel für Hohlraum-strahlung" von E. Warburg.

"Prüfung der Planck'schen Strahlungsgleichung im langwelligen Spectralbereich" von $H$. Rubens.

"Die Gesetze der Warmestrahlung und die Hypothese der elementaren Wirkungsquanten"

von M. Planck.

"Die kinetische Theorie der ideale Gase und die Versuchsresultate"

von M. Knudsen.

"Les preuves de la réalité moléculaire (étude speciale des émulsions)"

par J. Perrin.

"Anwendung der Quantentheorie auf eine Reihe physikalisch-chemischer Probleme" von W. Nernst.

"Die Bedeutung des Wirkungsquantums für unperiodische Molekularprozesse in der Physik"

von A. Sommerfeld.

"La théorie cinétique du magnétisme et les magnétons"

par P. Langevin.

"Zum gegenwärtigen Stande des Problems der spezifischen Wärme"

von A. Einstein.

Solvay II: "La structure de la matière".

List of participants

Chair: H.A. Lorentz (chairman of the Scientific Committee of the International Solvay Institute of Physics and chemistry)

Other Members of the Scientific Committee:

Mme Curie (Paris), M. Brillouin (Paris), W. Nernst (Berlin), E. Warburg (Charlottenburg), M. Knudsen (Copenhagen), E. Rutherford (Manchester), H. Kamerlingh Onnes (Leiden), R.B. Goldschmidt (Brussels). 
Invited members: Members of Solvay I and new members:

Sir J.J. Thomson (Cambridge), W.H. Bragg (Leeds), W. Barlow (Stanmore), G. Gouy (Lyon), W. Voigt (Göttingen), Ph. Lenard (Heidelberg), M. Laue (Zurich), W.J. Pope (Cambridge), W.C. Röntgen (Munich), P. Weiss (Zurich), E. Grüneisen (Charlottenburg), R.W. Wood (Baltimore).

Two members, Ph. Lenard and W.C. Röntgen, did not attend the meeting.

Secretary: R.B. Goldschmidt

Collaborators of Ernest Solvay: E. Herzen and G. Hostelet (Brussels)

Solvay reports:

"The Structure of the Atom"

by Sir J.J. Thomson.

"Die Interferenzerscheinungen an Röntgenstrahlen, hervorgernfen durch das

Raumgitter der Krystalle"

von M. von Laue.

"The Reflection of X-Rays and the X-Ray Spectrometer"

by W.H. Bragg.

"The Relation between Crystalline Structure and Chemical Constitution"

by W. Barlow and W.J. Pope.

"Quelques considérations sur la structure des cristaux et l'anisotropie des molécules. Dimorphisme du carbonate de calcium"

par M. Brillouin.

"Ueber die Abhängigkeit der Pyroelektrizität von der Temperatur"

von W. Voigt.

"Molekular Theorie der festen Körper"

von E. Grüneisen.

"Resonance Radiation and Resonance Spectra"

by R.W. Wood.

The Editors,

Franklin Lambert, Frits Berends, Michael Eckert 


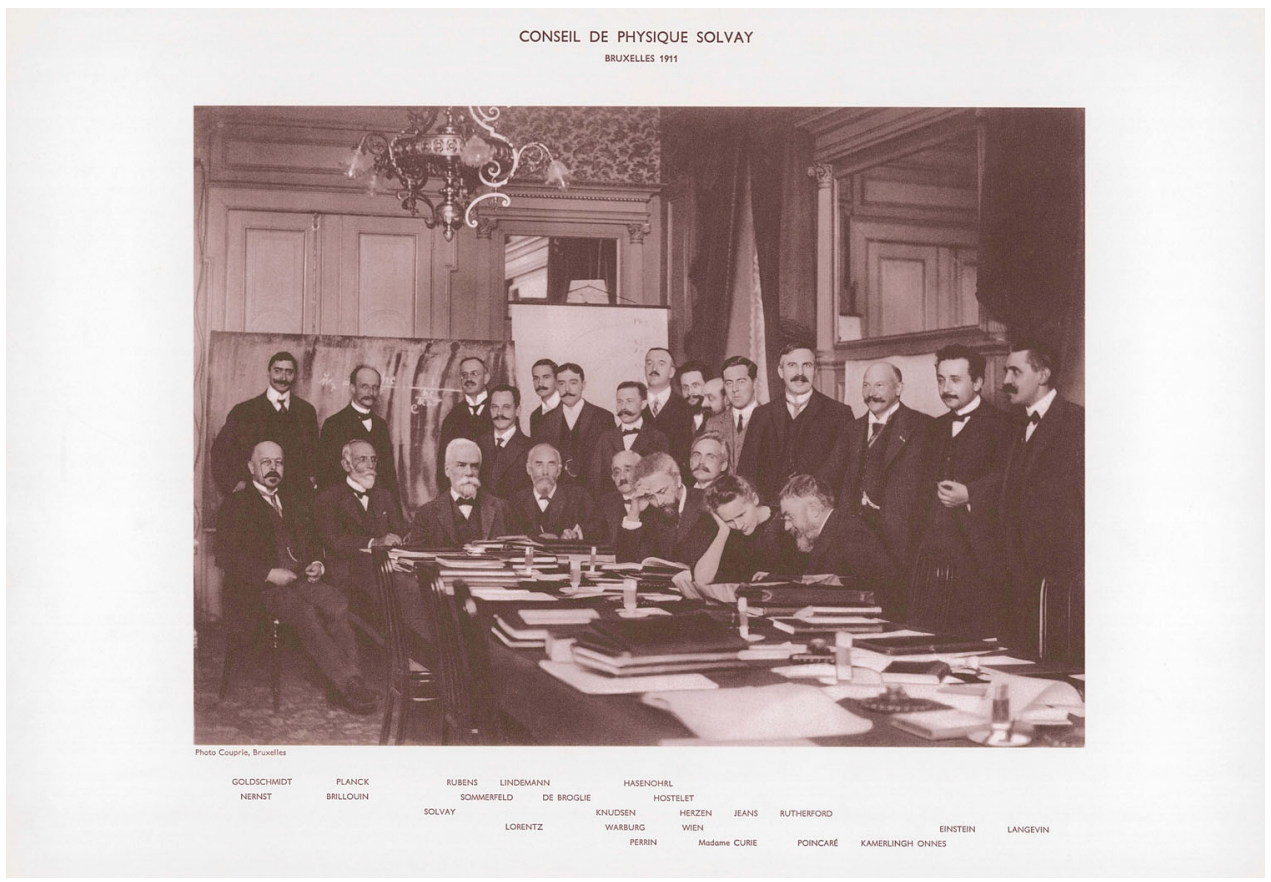

This is the well-known photo of Solvay I, taken on 31 October 1911 after Planck's presentation of his report (part of Planck's radiation formula is visible on the blackboard).

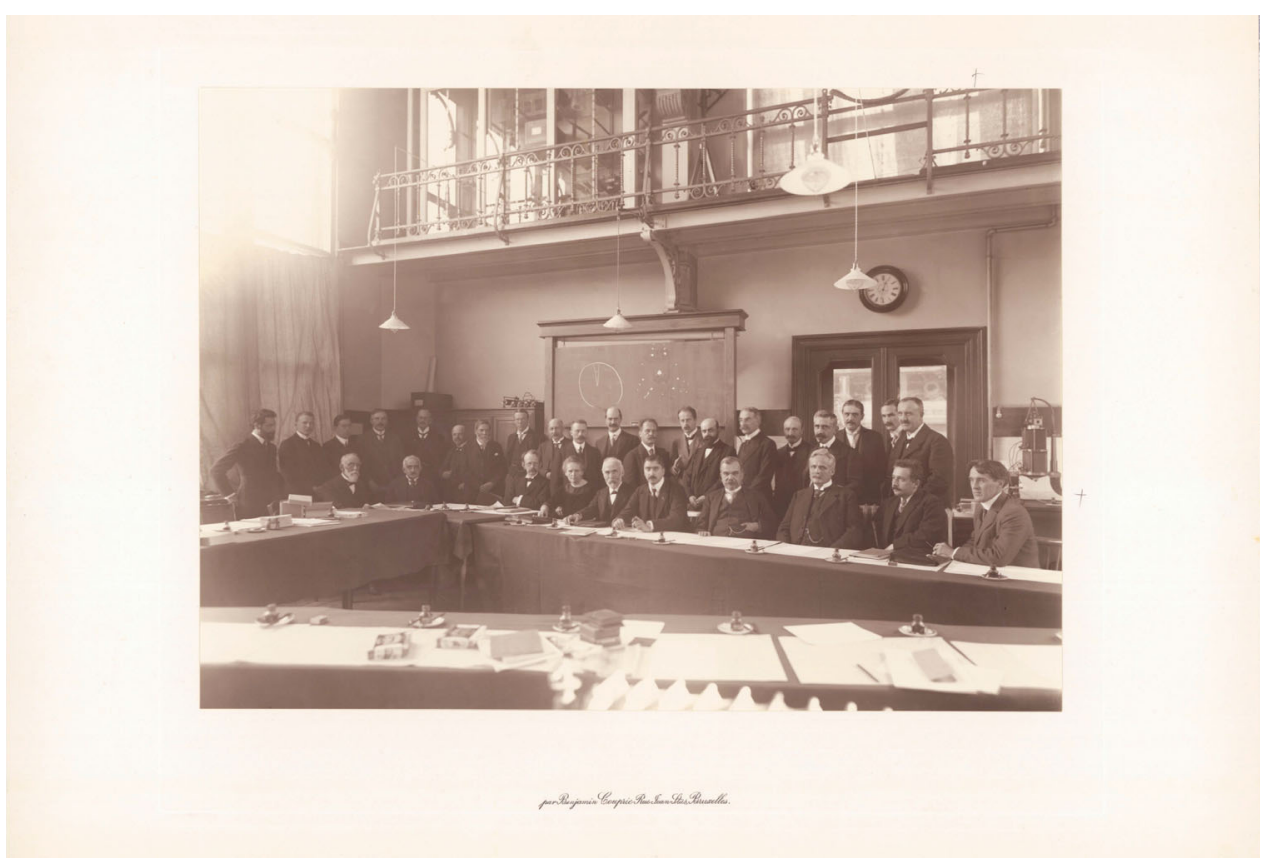

This is a less-known "indoor photo" of Solvay II. 